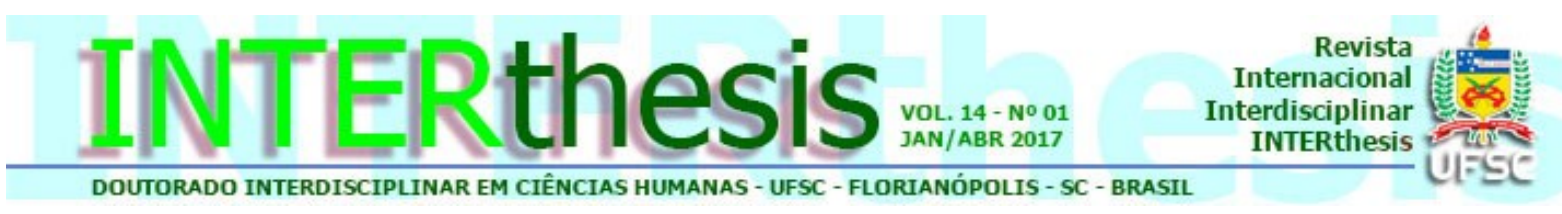

\title{
A LOUCURA NA VILA: REFLEXÕES SOBRE A LOUCURA EM TIRADENTES
}

\section{Resumo:}

David Inácio Nascimento ${ }^{1}$

O presente artigo tem como objetivo analisar as condições políticas e econômicas da Vila São José del-Rei, atualmente Tiradentes-MG, que possibilitaram a loucura ser aceita naquele espaço e, consequentemente, romper com os procedimentos de exclusão nos quais os loucos eram sujeitos em outras cidades mineiras. Tendo em Michel Foucault discussões sobre os procedimentos de exclusão da loucura e biopoder, o artigo busca, mediante os levantamentos históricos sobre a Vila de São José del-Rei, do início do séc. XVIII até o final do séc. XX, realizar paralelos com outras vilas e cidades mineiras do ciclo minerador e apontar nesses contextos possibilidades que rompem com os procedimentos de exclusão.

Palavras-chave: Loucura. Tiradentes. Filosofia. História. Foucault.

\section{INTRODUÇÃO}

Entre os meses de junho e julho de 1973, Michel Foucault veio ao Brasil para participar de uma série de atividades nas universidades brasileiras, incluído uma conferência feita em Belo Horizonte sobre as instituições psiquiátricas (FOUCAULT, 2011b, p. 42), é nesse momento no qual o francês aproveita um convite para conhecer algumas cidades históricas de Minas Gerais (ARBEX, 2013, p. 199). Enquanto o autor de "A História da Loucura" se juntava às outras vozes críticas à psiquiatria e ao internamento dos loucos, longe dos holofotes, estava um dos lugares visitados pelo francês naquela oportunidade: Tiradentes, cidade colonial originada na Vila de São José del-Rei e que, naquele momento, aos poucos via chegar ao fim um longo período de decadência econômica e política.

Em Tiradentes, até o final da década de 1980 e início da de 1990, era comum encontrar alguns loucos por suas ruas, fossem eles dali ou vindos de outros lugares, como Bichinho (Vitoriano Veloso), distrito de Prados. Além de ter certa "liberdade" no deslocamento dos ditos loucos, poderia chamar atenção a forma como a cidade e seus moradores se relacionavam e os incluíam. As mudanças econômicas e políticas passadas por Tiradentes ao longo de seus quase trezentos anos poderiam

\footnotetext{
${ }^{1}$ Mestre em Teoria Literária e Critica da Cultura pela Universidade Federal de São João del-Rei, São João del-Rei, MG, Brasil. Presidente do Instituto Histórico e Geográfico de Tiradentes, Tiradentes, MG, Brasil. E-mail: datanisgrego@yahoo.com.br
} 
dar indícios de como eram as condições que possibilitaram certas relações, já que, diferente de outras cidades mineiras do ciclo do ouro, o lugar não teve grande desenvolvimento econômico a partir da queda da produção aurífera, o que influenciou as relações de trabalho e sua organização.

A discussão sobre a loucura e seu processo histórico não é novidade, sendo esse processo dado a conhecer na tese defendida por Michel Foucault, posteriormente publicada como livro. Mediante as leituras permitidas em Foucault, ocorreu a possibilidade de uma pesquisa específica, tratando de um espaço conhecido e pouco conhecido, visível e pouco visto: a vila. Especificamente, Tiradentes enquanto espaço permitido ao louco. Diante disso, esse artigo tem como objetivo elaborar um pequeno levantamento histórico sobre o desenvolvimento econômico e político da cidade do séc. XVI ao XVIII e analisar como a decadência da Vila de São José del-Rei/Tiradentes possibilitou uma forma diversa de relacionamento entre os ditos "loucos" e os "normais".

\section{BREVE HISTÓRICO}

A povoação de "Tiradentes" teve início em 1702, quando o taubateano João de Siqueira Afonso encontrou veios de ouro nas encostas da Serra São José, dando origem ao que, inicialmente, foi chamado de Arraial da Ponta do Morro, depois conhecido como Arraial Velho do Rio das Mortes (VELLOSO, 2013, p. 16), já que, em 1704, surge o Arraial Novo, posteriormente Vila de São João del-Rei e, atualmente, cidade de São João del-Rei (SANTOS FILHO, 2012a, p. 1).

Foi nessa região, segundo o historiador tiradentino Herculano Velloso (18621941), dedicado a pesquisar "as memórias" da vila no tempo colonial, que, entre 1707 e 1708, por motivo de "cubiça" (sic.), aconteceu o conflito conhecido como a "Guerra dos Emboabas". Segundo Herculano Veloso, "a abundância de ouro atraiu desde logo a imigração, tanto paulista como a portuguesa, e, pouco tempo depois da sua descoberta, era a Ponta do Morro arraial importante" (VELLOSO, 2013, p. 18). Além da quantidade encontrada, o ouro de aluvião era de fácil extração, o que chamava atenção para o arraial. $O$ fim da guerra se deu com a retirada das tropas paulistas do cerco ao arraial, indo para Goiás e deixando aos emboabas a exploração do ouro e a acusação de deslealdade no episódio conhecido como "Capão da Traição". 
Foi compreendendo a dificuldade dos moradores do Arraial Velho em atravessar o Rio das Mortes até a Vila de São João del-Rei, responsável pela administração do Arraial Velho, que, em 19 de janeiro de 1718, respondendo aos pedidos dos moradores do ainda arraial, D. Pedro de Almeida, então governador da Capitania de São Paulo e das Minas do Ouro e futuro conde de Assumar, elevou o Arraial Velho à categoria de vila, sendo nomeada Vila de São José del-Rei. A elevação à vila foi confirmada pela coroa portuguesa em 12 de janeiro de 1719 (SANTOS FILHO, 2010, p. 16-17), sendo o Rio das Mortes a divisa entre as duas vilas (VELLOSO, 2013, p. 102). Assim, "a Vila de S. José, graças à riqueza de suas lavras, teve rápido desenvolvimento, maior que o de $\mathrm{S}$. João, tornando-se o seu termo, pela fecundidade do terreno, o mais abundante da capitania" (VELLOSO, 2013, p. 41), possuindo no ano de 1729 a quantia de 5.419 escravos; 17 lojas; 106 vendas; 75 ofícios; enquanto a Vila de São João del-Rei possuía 3.448 escravos; 14 lojas; 49 vendas; 48 ofícios (VELLOSO, 2013, p. 42).

No final do séc. XVIII, com o crescimento político e econômico dos arraiais que faziam parte da vila, São José del-Rei, que divisava território com Goiás (SANTOS FILHO, 2010, p. 18) e foi "um dos núcleos mais importantes no movimento da Inconfidência Mineira" (SANTOS FILHO, 2010, p. 20), passou a sofrer processos de desmembramentos, dando origem às novas vilas, como ocorreu com o próprio Arraial Velho quando passou à condição de vila, em 1718. Assim, em 1789, perde o território do Arraial de S. Bento do Tamanduá, atual Itapecerica; em 1790, perde o Arraial dos Carijós, atual Conselheiro Lafaiete; e, em 1791, perde o arraial de Nova Campolide, atual Barbacena (VELLOSO, 2013, p. 71). Esse processo continuou durante os sécs. XIX e XX, tendo o último desmembramento ocorrido no fim do séc. XX, quando o distrito de Santa Cruz de Minas se tornou cidade, em 1995. Ainda tratando do séc. XVIII, em 1795, por ocasião da desobriga ${ }^{2}$, o Pe. Manoel Gomes de Souza fez levantamento dos confessados da freguesia de Santo Antônio da Vila de São Jose del-Rei, contabilizando 10.926 habitantes e 1.727 fogos $^{3}$ (VELLOSO, 2013, p. 74-75), demonstrando seu tamanho e importância.

\footnotetext{
2 Tal informação está no "Rol dos Confessados", livro no qual o Pe. Manoel Gomes de Souza anotou os nomes dos que cumpriram com a obrigação anual de comungar e confessar. $\mathrm{O}$ documento, fonte de várias pesquisas e que hoje está aos cuidados do Instituto Histórico e Geográfico de Tiradentes, poșsui outras informações, embora trate apenas da "freguesia" da paróquia de Santo Antônio, não incluindo todo o território da vila.

${ }^{3}$ Fogos era a forma como as residências eram chamadas, por possuírem fogões à lenha
} 
Para a Vila de São José, o séc. XIX talvez possa ser descrito por seus altos e baixos: pelo esgotamento das minas de ouro; a emigração; e a supressão do município:

Grande parte da população que fizera fortuna na época áurea desceu para o Vale do Paraíba e passou a dedicar à cafeicultura, formando as novas cidades do ciclo do café. A comarca do Rio das Mortes sobreviveu quase exclusivamente da agricultura e da criação de suínos, destinadas à venda no Rio de Janeiro. Produziam-se também na região cal e telha em grande escala, além de algodão [...]. No extremo da decadência, o município de São José foi suprimido pela Lei Provincial n. 360 , de 30 de setembro de 1848 , sendo restaurado um ano depois pela Lei 463 , de 20 de outubro de 1849 (SANTOS FILHO, 2010, p. 22).

Ainda de modo a reforçar os altos e baixos passados pela vila, em 7 de outubro de 1860, a Vila de São José ganhou "os foros de cidade pela Lei 1.092" (SANTOS FILHO, 2010, p. 22), mantendo o nome de São José del-Rei. Em 1881, teve inaugurado o trecho da Estrada de Ferro Oeste de Minas, que passava por seu território e ligava São João del-Rei ao Sítio (atual cidade de Antônio Carlos). A mudança de nome de São José del-Rei para Tiradentes só ocorreu no final de 1889, tendo sido sugerida por Silva Jardim, quando o entusiasta da causa republicana discursou na estação da cidade, ao passar por São José del-Rei (SANTOS FILHO, 2010, p. 23). Entre 1899 e 1900, a cidade possuía

194 casas bastante arruinadas, sendo 19 sobrados. O município era constituído pelo distrito sede, Barroso e Lage [...] a população contava 11 mil habitantes, dos quais 3.500 viviam na sede do município. A economia baseava-se na agropecuária, exportação de queijos, exploração de caulim, oca e cristais, além de pequena produção aurífera (SANTOS FILHO, 2010, p. 24-25).

Já no séc. XX, em 1915, a cidade recebeu a instalação de canos para distribuir a água (antes, a principal fonte de abastecimento era o Chafariz São José, de 1749); depois da instalação hidráulica, em 1923, Tiradentes teve suas 24 lamparinas à querosene (que iluminavam algumas ruas da cidade) substituídas por postes com lâmpadas. Algumas ações foram tomadas no sentido de "preservar" as construções da cidade, como a Lei Municipal $n^{\circ}$ 6, de 18 de nov. de 1892, promulgada pela Câmara Municipal "proibindo a demolição de sobrados de porte, para reaproveitamento do material" (SANTOS FILHO, 2015, p. 20). Contudo, foi o tombamento do "conjunto 'arquitetônico e urbanístico' da cidade [...] em 20 de abril de 1938" (SANTOS FILHO, 2015, p. 36) o fator preponderante para que a cidade viesse prosperar no final do séc. XX. O tombamento pelo SPHAN (IPHAN) foi responsável pela salvaguarda do patrimônio arquitetônico que estava se perdendo 
com o abandono da cidade, devido seu empobrecimento político e financeiro durante os sécs. XIX e XX. Assim observado, a partir de tal empobrecimento e dos desmembramentos em novas vilas e cidades, Tiradentes se retrai e perde sua importância no cenário político. Um exemplo disso foi a supressão do município em 1848, quando São João del-Rei passa a responder pela vila. Mesmo a importância política possuída poderia ser em parte associada ao poder econômico e político de seus distritos (Barroso; Lages, atual Resende Costa; Santa Cruz). A título de comparação, enquanto a Vila de São José via outras vilas surgirem de seus arraiais na última década do séc. XVIII, um século depois, em 1893, São João del-Rei e Barbacena foram credenciadas à eleição para a nova capital do Estado de Minas Gerais, embora tenham sido derrotadas por Curral del-Rei (hoje, Belo Horizonte).

É nesse cenário que está uma possibilidade de análise da loucura na "vila": embora não existam documentações primárias que tratem dos ditos loucos durante os quase dois primeiros séculos da vila e um século e meio da cidade, a decadência econômica e política possibilitava uma problematização das relações de trabalho, das relações sociais e mesmo da não inclusão da cidade em um sistema econômico que impusesse a seus membros um modo de exaurir seu tempo que não fosse com o trabalho.

\section{A LOUCURA NAS CIDADES}

Tiradentes possuí um abrigo, o Abrigo Tiradentes, fundado em 1954; uma APAE, funcionando desde a última década do séc. $X X$, e tem sede própria desde a primeira década do séc. XXI; e uma "Unidade Mista de Saúde”, construída entre o final e início dos sécs. XX e XXI, para menor dependência de São João del-Rei. Sua cadeia pública, que nos últimos anos de funcionamento se tornou prisão feminina, foi fechada no final da década de 1950. Em suma, tais instituições poderiam ser aquelas nas quais seria focado o controle do biopoder sobre os internos. Para realizar uma problematização sobre a loucura "na vila", é necessário, além da compreensão econômica e política de Tiradentes, a compreensão do lugar de Tiradentes junto à outras cidades do período colonial mineiro: como Diamantina, São João del-Rei e Barbacena.

Um dos paralelos possíveis é Diamantina, cidade na qual a construção de seu hospício se "fez por um processo de modernização que acontecia em 
Diamantina no final do século XIX" (MAGNANI, 2008, p. 19), parte de um "processo que se dá nacionalmente enquanto redefinição de um projeto civilizatório com o olhar voltado para a Europa" (MAGNANI, 2008, p. 30), sendo também uma resposta à preocupação com o empobrecimento e ociosidade devidos à diminuição da mineração, pois a população da cidade havia passado de 12.354 moradores, entre 1.832-1.840, para 30.412, em 1.890 (MAGNANI, 2008, p. 32).

Assim como a Vila São José del-Rei, Diamantina passou por crise na sua mineração, devido a queda dos preços dos diamantes. Como era difícil o desenvolvimento da agropecuária, dado o solo impróprio, a cidade buscou saída na indústria dos tecidos como "alternativa de sobrevivência econômica" (MAGNANI, 2008, p. 31). Então, o surgimento do hospício em Diamantina é entendido menos como uma questão da dita "modernização" prometida e mais como um reflexo da industrialização e do combate à ociosidade e pobreza. É preciso, contudo, romper em parte com uma problematização meramente econômica (como se a instituições se desenvolvessem por causa da econômica e não inversamente ou de forma imbricada) e introduzir outra possibilidade de análise. Segundo Foucault, entre os sécs. XVII e XVIII, surge uma forma de "mecânica do poder" incidindo "primeiro sobre os corpos e sobre o que eles fazem, mais do que sobre a terra e sobre o seu produto. (...) permite extrair dos corpos tempo e trabalho, mais do que bens e riqueza" (FOUCAULT, 2010b, p. 31). Com essa mecânica, há toda uma elaboração de espaços como os das fábricas, escolas, quartéis, hospitais, hospícios, etc. Espaços propícios para a observação dos corpos, para extrair deles também o saber. Assim, a atenção para com estas instituições deve considerar a participação delas nas relações imbricadas entre saber e poder.

Embora o hospício de Diamantina só tenha seu início no final do séc. XIX, sua Santa Casa, assim como a Santa Casa da Misericórdia de São João del-Rei, já funcionava no final do séc. XVIII, ambas fundadas pelo ermitão Manuel de Jesus Fortes (MAGNANI, 2008, p. 35). O que as diferia era o "patrocínio" da Irmandade da Misericórdia dado para a Santa Casa de São João del-Rei, enquanto a Santa Casa de Diamantina enfrentava problemas financeiros, tendo gastos que não eram para "com a saúde". Em 1872, por exemplo, surgem reclamações de que a instituição de Diamantina "abusava" em receber "inválidos incuráveis e mendigos" (MAGNANI, 2008 , p. 42), por isso a construção do hospício se apresentou como uma forma de 
unir caridade e limpeza das ruas (MAGNANI, 2008, p. 43). Enquanto a Santa Casa de São João del-Rei é considerada por alguns o primeiro hospital geral do Brasil "a possuir unidades psiquiátricas, localizando a primeira internação de um doente mental em 1817 [...] o primeiro hospício de alienados de Minas Gerais foi o Hospício da Diamantina, cuja pedra fundamental foi fixada em 1888" (MAGNANI, 2008, p. 45).

Assim como a Santa Casa de Diamantina recebeu reclamações, também o hospício foi criticado pela população: a população "não só se negava a aceitar com naturalidade a prisão e os maus tratos dispensados aos loucos, como há indícios de que controlava as ações do hospício e se mobilizava no sentido de denunciar qualquer suspeita de tratamento agressivo" (MAGNANI, 2008, p. 62). Menos de 20 anos após sua inauguração, em 1906, o hospício contava com quatro pacientes que não puderam ser transferidos para Barbacena, pois a falta de recursos o fez ser fechado: "assim como o surto industrial de Diamantina no século XIX, ou seu processo modernizador, o hospício foi uma promessa que não se cumpriu" (MAGNANI, 2008, p. 63). Tese assim apresentada por Magnani, o hospício fechou suas portas junto da "promessa de modernização da cidade", por não ter suficientes "representação política e econômica" (2008, p. 83). Diamantina se "equipara" à Vila de São José del-Rei após a decadência aurífera e política. No caso de Diamantina, isso pode ser evidenciado nas reclamações e denúncias da população quanto aos maus tratos cometidos.

Em Barbacena, o hospício foi construído no terreno onde antes havia a Fazenda da Caveira, de Joaquim Silvério dos Reis, denunciante da Inconfidência Mineira. Depois de fazenda, lá foi instalado um hospital particular para tratamento de tuberculosos e, em 1900, passa a funcionar a "Assistência aos Alienados". A criação do hospício aconteceu no ano de 1903, mesmo ano da "Lei de Assistência aos Alienados" (COSTA, 2007, p. 40), criada sob a influência de Teixeira Brandão (PASSOS, 2009, p. 106). Os maus tratos em Barbacena foram evidenciados pela série de reportagens feitas por Hiram Firmino para o jornal "O Estado de Minas", depois publicadas no livro "Nos porões da loucura" (1982). Em uma das reportagens, ao ser questionado sobre o motivo do hospício ter sido construído em Barbacena, o diretor do Colônia, o médico José Theobaldo Tollendal, disse:

- Vocês são novos ainda. Isso aqui é terra de políticos. Este hospital foi
criado em Barbacena por questões meramente políticas. Jamais foi
considerado o aspecto médico-terapêutico desta cidade que, a meu ver,
deveria ter sido a última a ser escolhida no País para este fim. Ao invés de R. Inter. Interdisc. INTERthesis, Florianópolis, v.14, n.1, p.79-97 Jan.-Abr. 2017 
construírem este hospital lá em Muriaé, em Carangola, numa região mais quente, eles preferiram aqui, por meros interesses pessoais. A preocupação não foi com a saúde de ninguém, e sim fazer disso aqui uma fonte de empregos, de votos para os senhores políticos da região. Basicamente, é isso. [...] Quero dizer, aqui em Barbacena, durante os meses de inverno, a temperatura cai a zero grau, permanecendo assim durante vários dias. Pensem bem o que isto significa para os nossos doentes? Pessoas que têm um vestuário pobre, apenas uma roupinha de brim, um cobertorzinho por cima do corpo. [...] Aumenta o obituário, imediatamente. [...] a própria introversão aumenta também. E agrava o seu estado físico-psicológico (FIRMINO, 1982, p. 56-57).

Além dessa indicação, há outro motivo a ser apontado para a construção do hospício em Barbacena, também por "influência política": a instituição teria sido um "prêmio de consolação" dado à cidade por ela "ter sido preterida para sediar a capital do estado em favor de Belo Horizonte" (PASSOS, 2009, p. 109). Seu idealizador e primeiro diretor (por três décadas) foi o médico Joaquim Antônio Dutra, formado em clínica médico-cirúrgica no Rio de Janeiro e então deputado estadual, "um dos que votaram contra a transferência da capital do estado para Belo Horizonte, sendo favorável a Barbacena, a qual indicou para sediar a Assistência aos Alienados" (PASSOS, 2009, p. 109). Com o passar dos anos, Barbacena também teve sua "decadência", não tanto política e econômica (como Tiradentes e Diamantina), mas de seu hospício que, já em 1924, enfrentava a superpopulação. Em 1919, com 270 vagas, possuía 428 internos; depois, em 1920, contava com 627 internos (PASSOS, 2009, p. 110). Já na segunda metade do séc. $X X$, a superpopulação fez proliferar o número de clínicas particulares. Tais clínicas, por vezes, "mantinham o paciente internado por todo o período que o INPS pagasse, mesmo que já tivesse condições de receber alta" (PASSOS, 2009, p. 111-112).

Logo, com a criação do hospício em Barbacena, os problemas sociais assim considerados pela cidade e seus políticos poderiam ser resolvidos, além de permitir a relação saber/poder. A internação em Barbacena se tornou solução para todas as mazelas: por mazelas, pode ser entendido aquilo que não é aceito pelos padrões instituídos por certos grupos. É algo a ser observado na descrição feita por Foucault sobre os internados nos asilos durante o séc. XVII:

[...] doentes venéreos, devassos, dissipadores, homossexuais, blasfemadores, alquimistas, libertinos: toda uma população matizada se vê repentinamente [...] rejeitada para além de uma linha de divisão, e reclusa em asilos que se tornarão, em um ou dois séculos, os campos fechados da loucura (FOUCAULT, 2010c, p. 102). 
É pertinente compreender que os grupos aos quais se destinam a internação e seus procedimentos mudam (considerando os recortes geográficos históricos). Mas não muda o fato de existirem grupos "matizados" e procedimentos de exclusão, após feitos exames e considerações quanto a normalidade e anormalidade (FOUCAULT, 2010a, p. 36). É nesse sentido que pode ser observada uma lei criada em São João del-Rei, em 1887, visando tratar "da limpeza e polícia urbana da cidade e povoações, dos cães, animais mortos, dos animais bravos ou danados e dos loucos". Dizia a lei: "Artigo 139 - Todo aquele que conservar sob sua guarda em sua casa qualquer louco, será obrigado a tê-lo com segurança, não o deixando vagar pelas ruas, sob pena de $10 \$ 000$, e a pagar qualquer prejuízo causado"4 (PASSOS, 2009, p. 105). No Brasil, as legislações constitutivas do "clima psiquiátrico que deu origem à Liga Brasileira de Higiene Mental" (COSTA, 2007, p. 42) ocorrem principalmente no início do séc. $X X$, intensificando a exclusão dos loucos e o ideal eugenista que classificava e, assim, defendia a sociedade do perigo dos degenerados ${ }^{5}$ (COSTA, 2007, p. 50-51).

Firmino (1982) indica a existência de uma movimentação financeira em torno do louco e de sua internação, não apenas com as clínicas particulares, mas também pelo trabalho forçado. Mas no caso citado de São João del-Rei, a multa teria menos o propósito de gerar receitas e seria mais uma forma de reforçar a exclusão do louco no seio da cidade naquele período, assim como nas casas de internação. Os internos estavam ligados pela incapacidade de "tomar parte na produção, na circulação ou no acúmulo de riquezas" (FOUCAULT, 2000, p. 79) e a exclusão a qual eram condenados "está na razão direta desta incapacidade e indica o aparecimento no mundo moderno de um corte que não existia antes" (FOUCAULT, 2000, p. 79), o internamento tem ligação "nas origens e no seu sentido primordial a esta reestruturação do espaço social" (FOUCAULT, 2000, p. 79).

Outras cidades podem partilhar da análise e pontuações feitas em relação à Tiradentes. A cidade de Prados-MG, por exemplo, foi uma das cidades pesquisadas por Izabel Christina Friche Passos em "Loucura e Sociedade: discursos, práticas e

\footnotetext{
4 Informação que Passos cita do trabalho de fim de curso de Helder Pereira "Loucos e esquadrinhadores na sociedade sanjoanense oitocentista: a dimensão do temor no universo racional", o qual não foi encontrado para ser pesquisado.

${ }^{5}$ Firmino publicou a carta de "João Batista da Silva" que, em 1979, tinha 28 anos. Casado e morador de Barbacena, foi internado por motivos de bebida, denunciou na carta (FIRMINO, 1982, p. 87).
} 
significações sociais" (2009). O livro trata da relação da cidade mineira com a loucura, como uma cidade que "não interna seus loucos" (PASSOS, 2009, p. 31). A análise feita sobre Prados pode ser trazida para o contexto de Tiradentes, em razão de Prados ter perdido sua importância geográfica com a abertura de novas estradas (PASSOS, 2009, p. 59), mantendo um desenvolvimento econômico aquém de outras cidades da região, como São João del-Rei (PASSOS, 2009, p. 60).

\section{LOUCURA E SOCIEDADE}

Como afirmou Foucault, a loucura só existe em uma sociedade, não existindo em estado selvagem (FOUCAULT, 2011b, p. 63). Ou seja, "cada cultura formará da doença uma imagem cujo perfil é delineado pelo conjunto das virtualidades antropológicas que ela negligencia ou reprime" (FOUCAULT, 2000, p. 72). Tal loucura, considerada ou não doença, tem suas "funções" na história e as funções vão se modificando de acordo com a sociedade que a toma, seja enquanto possibilidade de saber, agir guiado pela caridade, desrazão a qual a razão vai se opor e se sobrepor, doença a ser curada, etc. Por isso, o louco também se modifica nessa sociedade: ele passa por exclusões que tratam da família e mesmo do trabalho, mas é também alvo de uma exclusão que trata do jogo no qual o colocam, como no caso das festas ou do no teatro do séc. XVI e XVII, quando o louco "é, antes, portador da verdade" (FOUCAULT, 2011b, p. 239). Embora todos outros os personagens ali possuam suas vontades, eles não possuem a verdade do louco. É ele quem a possui, embora não domine seu comportamento e nem suas vontades. Mas nesses jogos "ele não é completamente excluído e, se assim é possível dizer, ele é ao mesmo tempo excluído e integrado, ou melhor, estando excluído representa um certo papel" (FOUCAULT, 2011b, p. 240).

Durante a Idade Média e renascimento "era permitido aos loucos existir no seio da sociedade" (FOUCAULT, 2011b, p. 265), mas, com o tempo, "a sociedade européia tornou-se intolerante para com os loucos. A causa foi [...] o começo da formação industrial" (FOUCAULT, 2011b, p. 265). Assim, perdendo o trabalho e a família, sua era a loucura a produzir sua verdade. Quanto a isso, a supressão dessa verdade e silenciamento do louco, é possível observar a ação dentro de um modo de agir concebido por um procedimento do biopoder. O biopoder "sem a menor dúvida, foi elemento indispensável ao desenvolvimento do capitalismo, que só pôde ser 
garantido à custa da inserção controlada por corpos no aparelho de produção e por meio de um ajustamento dos fenômenos de população aos processos econômicos" (FOUCAULT, 1988, p. 153). Em suma, os desenvolvimentos do capitalismo e das condições de produção podem ser associados ao biopoder que marcava e controlava os corpos, inserindo-os em certos espaços de controle e extraindo deles saber e poder. Trata-se de uma mecânica do poder que modificou as formas das relações, das relações de trabalho e da gestão do tempo e da vida, algo preponderante na observação do papel do louco e da loucura na sociedade, especialmente quanto a passagem da permissão de existir e participar das festas e vida social (ainda que condicionada) ao internamento.

Os internamentos nos hospícios estão ligados à política, ao modo como os médicos desde o séc. XIX se ligavam a ela (MACHADO et al., 1978, p. 197). Fazem parte dessa mecânica do poder que age na forma como os homens se constituem social e politicamente. Além disso, de toda a economia produzida pelos internamentos quanto ao saber e poder emergentes neles, os internamentos eram também ligados a uma "política menor", imediata, já que os pedidos de internação algumas vezes vinham não só de médicos e "psicólogos", mas também de "deputados, prefeitos e polícia militar" (PASSOS, 2009, p. 119).

Retornando a Tiradentes, o levantamento político e econômico feito demonstrou a queda da importância da "vila" no cenário político e econômico da região. Uma vez afastados desse cenário político econômico, as relações de trabalho, a exploração dos corpos, o encarceramento dos corpos, a movimentação econômica, etc. e, principalmente, a motivação para existência da construção de instituições de controle que funcionem com a relação saber e poder tomam uma forma diferente. De certo modo, com a perda de sua importância, a vila, além de conservar certo modelo de organização social, não atraiu o aparato que permitia outros modos de organização (como inicialmente ocorreu em Diamantina), possibilitados ou centrados principalmente no poder e saber científicos que se apoiavam na medicalização e internação dos loucos. Com isso, não apenas não possuía instituições de controle, a cidade não se preocupava com o propósito da internação e do controle instituído pelo poder e saber. Os chamados "loucos de rua" eram comumente encontrados nas ruas da cidade, fazendo parte dela: Tiradentes perdeu seu lugar de importância; perdeu parte de sua aristocracia (que vai investir 
no Vale Paraíba); não desenvolveu sua economia e a constante necessidade de produção e aglomeração de riqueza, de controle e exploração dos corpos e combate aos grupos "improdutivos".

É preciso compreender que "o desenvolvimento econômico produz também os efeitos negativos na vida dos indivíduos" (FOUCAULT, 2011a, p. 307) e, no caso de Tiradentes, o não desenvolvimento e também a regressão econômica e política durante o séc. XIX desembocam no abandono temporário da cidade; na inexistência de instituições de controle e exclusão; na não incorporação de saberes científicos, medicalização e internação dos loucos; além da perda de parte do seu patrimônio arquitetônico (SANTOS FILHO, 2010, p. 24), que só será foco de políticas de preservação a partir do tombamento da cidade pelo IPHAN. Por conta disso, os efeitos negativos do desenvolvimento econômico da cidade só serão visíveis com a transformação da cidade em destino turístico, no final do séc. $\mathrm{XX}$, quando a cidade passa a receber capital externo e sofrer com a especulação imobiliária e esvaziamento de seu centro histórico, já que as residências, se não eram compradas para servirem como casas de temporada, acabavam usadas como pontos comerciais. Os procedimentos de exclusão que não ocorreram antes, quando não havia internamento dos loucos, passam a acontecer em um processo de gentrificação no final do séc. XX e início do XXI.

\section{CURTO ESTUDO DE CASO: VICENTE VELLOSO, "BOLAS PELOTAS"}

Vicente de Paula Velloso ${ }^{6}$ nasceu no ano de 1889 , em Tiradentes, sendo filho de Dona Maria José Velloso, zeladora da Matriz de Santo Antônio, e de Francisco Joaquim Ribeiro. Segundo Rodrigues Santos (2012b), pelo envolvimento religioso de sua mãe; também de seu irmão, Padre João Teodorico; e de seu padrinho, Padre João da Batista Fonseca, Vicente Velloso entra para o Seminário de Mariana, ainda menino, para obter os estudos e se ordenar padre.

Com o tempo, ao perceber que não possuía vocação sacerdotal, Vicente Velloso deixa o seminário e, no início do séc. XX, assume o cargo de "contador e distribuidor do fórum de Tiradentes", o qual ocupará até se aposentar. "Homem de rara inteligência", Vicente Velloso estudou latim no seminário e música no "Clube Euterpe Tiradentino", tendo se tornado "exímio músico e compositor". Segundo

6 As referências aqui encontradas nos foram possíveis devido a informações do historiador Tiradentino e pesquisador do IPHAN, Olinto Rodrigues dos Santos Filho.

R. Inter. Interdisc. INTERthesis, Florianópolis, v.14, n.1, p.79-97 Jan.-Abr. 2017 
Santos Filho (2012b), "a demência o atacou ainda com pouca idade. Contava-se que foi por uma desilusão amorosa, uma paixão por uma certa Alice, que durou até o fim da vida". Embora parte da cidade entenda sua loucura advinda de tal desilusão, Vicente Velloso possuía outras duas irmãs que, segundo a tradição tiradentina, também eram tidas como loucas: Maria do Gato e Nhanhá, o que também teria sido tratado como uma predisposição familiar. Algumas vezes, sua loucura ainda foi associada à sua inteligência tida como incomum. Membro de uma família de certa notoriedade ${ }^{7}$, Vicente Velloso, apelidado de "Bolas Pelotas", andava pela cidade mal vestido, como abandonado, podendo o associar ao chamado "louco de rua". Era, ao mesmo tempo, atormentado pelas crianças e respeitado pelos mais velhos e, com certa frequência, se alimentava na casa desses. Com isso, também era notório seu movimento pela cidade, aquilo que o fazia atrair a atenção de crianças e turistas e ser digno de respeito por outros.

\begin{abstract}
Com suas longas barbas grisalhas, um surrado sobretudo cinza e um bastão, a figura do ancião impressionava a todos e assustava as crianças do nosso tempo. Vicente Velloso era conhecido pelo apelido de "Bolas Pelotas", que ele odiava. Contava-se que com a demência ele certa vez ouviu o nome da cidade de Pelotas-RS e passou a murmurar pelas ruas: "Ora, como pode uma cidade chamar-se Pelotas... ora bolas Pelotas..." Daí o apelido, gritado pelas crianças, pelas ruas da cidade. Trazia o velho Velloso sempre um terço na mão, a murmurar pelas ruas palavras em latim, sempre perambulando ou sentado no adro da matriz, posando para pintores ou assustando crianças (SANTOS FILHO, 2012b).
\end{abstract}

A identificação de Vicente Velloso como um ancião, dado sua vestimenta e cajado, era reforçada por sua inteligência e mesmo pelo trato que demonstrava ter. Quer dizer, ainda que fosse atormentado e respondesse as provocações das crianças, podia ser encontrado no adro da Matriz de Santo Antônio posando para fotógrafos ou pintores ${ }^{8}$ e causando estranhamento devido seu conhecimento, explicitado por saber falar latim. Nesse caso, o estranhamento ainda poderia ser dado pela dualidade "existente" entre loucura e razão, ou razão e desrazão. Assim, talvez onde houvesse loucura seria esperado que não houvesse razão ou saber, quase associando o louco a um ser irracional, não possuidor de verdade. No "jardim das espécies", como tratou Foucault, o louco com a sua loucura é observado em suas relações com as outras formas de existência naquele espaço. O louco não

\footnotetext{
7 Fazem parte da família Veloso o Frei Mariano da Conceição Veloso, botânico e autor de "A Flora Fluminense", diretor da Casa Tipográfica Arco do Cego, em Lisboa, Portugal, e primo de Tiradentes; e Herculano Veloso, historiador e político Tiradentino.

${ }^{8}$ Dentre os registros disponíveis, há uma fotografia publicada na revista "O Cruzeiro", feita em 1967.
} 
deixa de participar do processo da alteridade que constitui o outro, mas é tomado como um "outro outro":

o louco é outro em relação aos outros; o outro - no sentido da exceção entre outros - no sentido do universal. Toda forma de interioridade é, agora, conjurada: [...] o relacionamento que o define entrega-o totalmente, através do jogo das comparações objetivas, ao olhar do sujeito razoável. Entre o louco e o sujeito que pronuncia "esse aí é um louco" estabelece-se um enorme fosso, que não é mais o vazio cartesiano do "não sou esse aí" mas que está ocupado pela plenitude de um duplo sistema de alteridade: [...] o louco é mais ou menos diferente no grupo dos outros que, por sua vez, é mais ou menos universal (FOUCAULT, 2010c, p. 183).

Já a sua loucura, ela

tem uma dupla maneira de postar-se diante da razão: ela está ao mesmo tempo do outro lado e sob seu olhar. Do outro lado: a loucura é diferença imediata, negatividade pura, aquilo que se denuncia como não-ser, numa evidência irrecusável; é uma ausência total de razão, que logo se percebe como tal, sobre o fundo das estruturas do razoável. Sob o olhar da razão: a loucura é individualidade singular cujas características próprias, a conduta, a linguagem, os gestos, distinguem-se uma a uma daquilo que se pode encontrar no não-louco; em sua particularidade ela se desdobra para uma razão que não é termo de referência mas princípio de julgamento; a loucura é então considerada em suas estruturas do racional (FOUCAULT, 2010c, p. 184, itálicos do autor).

Se alguns dos atos de Vicente Velloso fazem-no ser associado aos loucos, outros atos (como falar latim) o colocam em outro grupo. É, ao mesmo tempo, louco de rua e partícipe de um saber específico, isso o fez se movimentar de um grupo a outro. Sendo louco a vagar em uma cidade que não interna seus loucos, despertou a caridade; sendo ancião, despertou curiosidade e respeito. Seus atos e loucura ainda o fizeram um outro entre os outros: as dimensões de sua loucura e figura o fariam "outro", fosse entre os loucos de rua ou entre os não-loucos. Sua loucura não era menos compreendida pelos possuidores da razão que a sua inteligência tida incomum.

O caso específico de sua pessoa permite a observação de algumas particularidades, principalmente do estranhamento. Longe do discurso da medicalização e tentativa de compreender racionalmente a loucura, a cidade de Tiradentes e seus moradores parecem ter na figura de Vicente Velloso um ser que rompe com as relações entre os cidadãos e os loucos: ele foi aceito, mas desperta a curiosidade sobre a causa da sua loucura. Já a busca pela compreensão de seu estado era diferente do que seria feito nos casos de medicalização e exortação da razão como algo que abarca e tem predominância sobre a loucura. Isso é, a curiosidade popular, em lugar de possuir um olhar fundamentado no distanciamento do sujeito/objeto, aproxima o louco e o inclui. Vicente Velloso, assim como suas R. Inter. Interdisc. INTERthesis, Florianópolis, v.14, n.1, p.79-97 Jan.-Abr. 2017 
irmãs Maria do Gato e Nhanhá, assim como tantos outros que poderiam ser encontrados vagando pela cidade até o final dos anos 80 ou meados dos anos 90, podem ser exemplos de que a aceitação social da loucura em uma cidade está associada ao seu desenvolvimento econômico que, por sua vez, está ligado ao modo de gerir tempo e espaço.

\section{CONCLUSÃO}

Para além da recuperação do louco no sentido terapêutico, sua recuperação social, trazê-lo de volta para a vida da cidade, é uma recuperação da própria sociedade. A manifestação da "loucura", assim como ocorria com o advento da Festa da Loucura, permite diagnosticar a própria sociedade diante de suas possibilidades de relações, da forma como acata a produção desejada pelo capitalismo e como trata da exacerbação da racionalidade instrumental e da exclusão daqueles que se distanciam dessa racionalidade. Essa exclusão talvez seja a exclusão de algo importante para a sociedade e que a sociedade não deveria excluir. Isso foi tratado por Foucault quando o autor falou da perda do sentido da Festa da Loucura, contra-festa que existiu durante a Idade Média possuindo importância político-religiosa para a sociedade (FOUCAULT, 2011b, p. 263). O controle e exclusão exercidos sobre os loucos e loucura parecem fazer surgir uma lacuna que viria a ser preenchida pela loucura sintética, drogas ou álcool (FOUCAULT, 2011b, p. 264).

A denúncia dos procedimentos de exclusão, a aceitação do louco e sua loucura e participação na sociedade sugerem que tal sociedade tenta certos rompimentos: seja com a racionalidade, como mediadora de um modo de vida; seja com a necessidade de produção e gestão da vida em um espaço e tempo; seja da organização sociopolítica que responde ao apelo de certas formações discursivas.

Quando perdeu parte de sua importância, a Vila de São José delRei/Tiradentes manteve um modo sui gereneris de organização social que permitiu experienciar a loucura livre das exclusões. Claro, isso não significa que tenham se relacionado em harmonia e nem que não houve internações, pois outros fatores podem ser preponderantes na decisão de internar alguém além do desenvolvimento econômico e político. Contudo, se de algum modo a presença da loucura permite tanto traçar um diagnóstico na sociedade, como elaborar uma crítica aos extremos 
da razão, mostrando que nem tudo responde a tal razão ou que nem tudo está num âmbito da ordem, situações como as da "vila" podem mostrar que quando a sociedade responde afirmativamente as condições de produção de riqueza ela insere o indivíduo em espaços cada vez mais excludentes.

Casos parecidos ao de Vicente Velloso, o "Bolas Pelotas", poderiam demonstrar que a loucura ainda é estranha e que, ao mesmo tempo, o louco é tomado como um outro com o qual ainda é possível se relacionar. A loucura, enquanto algo estranho, torna-se exemplo de sua tomada como objeto a ser exaurido e conhecido, algo que estava ligado ao contexto da cidade naquele momento, mas que era tomado de forma diferente. Além de Vicente Velloso, outros loucos se tornaram "célebres" em Tiradentes, muito pela acolhida e não exclusão sofrida, demonstrando que, embora fosse estranha à cidade, a loucura não se mostrava um perigo, o que dava ao louco a permissão para existir. 


\title{
MADNESS IN A VILLAGE: REFLECTIONS ON THE MADNESS IN TIRADENTES
}

\begin{abstract}
:
This article aims to analyze the political and economic conditions of Vila São José del-Rei, now Tiradentes (Minas Gerais), that allowed madness to be accepted, thus breaking the exclusion procedures common to the same region. By some discussions made by Michel Foucault on madness about exclusion procedures and biopower, this article seeks to make parallels between the village of São José del-Rei and other villages and Minas Gerais colonial cities from the century XVIII to the end of the century $\mathrm{XX}$, and points out the possibilities that break with the exclusion procedures.
\end{abstract}

Keywords: Madness. Tiradentes. Philosophy. History. Foucault.

\section{LOCURA EN LA ALDEA: REFLEXIONES SOBRE LA LOCURA EN TIRADENTES}

\section{Resumen:}

En este artículo se analizan las condiciones políticas y económicas en la Villa de São José del-Rei, ahora Tiradentes, Minas Gerais, que possibilitaron que la loucura sea aceptada en aquel espacio y, consequentemente, rompe con los procedimientos de exclusión de los locos a los que eran sujetos en otras ciudades de Minas Gerais. Con algunas de las discusiones realizadas por Michel Foucault sobre los procedimientos para la exclusión de la locura, en este artículo se pretende hacer un paralelismo entre el pueblo de São José del-Rei y otras aldeas y ciudades coloniales de Minas Gerais desde el siglo XVIII hasta finales del siglo XX y señalar, en esos contextos, las posibilidades que rompen con los procedimientos de exclusión.

Palabras clave: Locura. Tiradentes. Filosofia. Historia. Foucault. 


\section{REFERÊNCIAS}

ARBEX, Daniela. Holocausto Brasileiro: genocídio de 60 mil mortos no maior hospício do Brasil. São Paulo: Geração Editorial, 2013.

BASSAGLIA, Franco. Psiquiatria Alternativa: contra o pessimismo da razão, o otimismo da prática - conferências no Brasil. São Paulo: Ed. Brasil Debates, 1979.

COSTA, Jurandir Freire. História da Psiquiatria no Brasil: um corte ideológico. Rio de Janeiro, Garamond, 2007.

FIRMINO, Hiram. Nos porões da loucura. Rio de Janeiro: Codecri, 1982.

FIRMINO, Hiram. A "via-crucis" de Maria, a Louca de Minas que desnudou a pisquiatria. Petrópolis: Vozes, 1986.

FOUCAULT, Michel. Arte, Epistemologia, Filosofia e História da Medicina. Rio de Janeiro: Forense Universitária, 2011a.

FOUCAULT, Michel. Em Defesa da Sociedade. São Paulo: Martins Fontes, 2010b.

FOUCAULT, Michel. Doença Mental e Psicologia. Rio de Janeiro: Edições Tempo Brasileiro, 2000.

FOUCAULT, Michel. Os Anormais: curso no Collège de France (1974-1975). São Paulo: Martins Fontes, 2010a.

FOUCAULT, Michel. História da Loucura: na Idade Clássica. São Paulo: Perspectiva, 2010c.

FOUCAULT, Michel. Problematizações do Sujeito: Psicologia, Psiquiatria, Psicanálise. Rio de Janeiro: Forense Universitária, 2011b.

GOFFMAN, Erving. Manicômios, prisões e conventos. São Paulo: Perspectiva, 2013.

INSTITUTO HISTÓRICO E GEOGRÁFICO DE TIRADENTES. Rol dos confessados. Blog do Instituto Histórico e Geográfico de Tiradentes, Tiradentes, 19 
de agosto de 2014. Disponível em <http://ihgt.blogspot.pt/2014/08/rol-dosconfessados.html >. Acesso em: 10 de janeiro de 2016.

MACHADO, Roberto et al. Danação da Norma: a medicina social e a constituição da psiquiatria no Brasil. Rio de Janeiro: Graal, 1978.

MAGNANI, Maria Cláudia Almeida Orlando. Hospício da Diamantina: a loucura na cidade moderna. Belo Horizonte: Argvmentvm, 2008.

MELLO, Carlos Gentile. Saúde e Assistência Médica no Brasil. São Paulo: HUCITEC, 1977.

PASSOS, Izabel Christina Friche. Loucura e Sociedade: Discursos, Práticas e Significações Sociais. Belo Horizonte: Argvmentvm, 2009.

SANTOS FILHO, Olinto Rodrigues dos. Guia da Cidade de Tiradentes: Arte e História. Tiradentes: Edição do Autor, 2012a.

SANTOS FILHO, Olinto Rodrigues dos. Vicente Velloso: Bolas Pelotas. Blog do Instituto Histórico e Geográfico de Tiradentes, Tiradentes, 3 de julho de 2012b. Disponível em < http://ihgt.blogspot.pt/2012/07/vicente-velloso-bolas-pelotas.html > . Acesso em: 10 de janeiro de 2016.

SANTOS FILHO, Olinto Rodrigues dos. A Matriz de Santo Antônio em Tiradentes. Brasília, DF: IPHAN/Monumenta, 2010.

SANTOS FILHO, Olinto Rodrigues dos. Tiradentes: Monumentos preservados. Tiradentes: IHGT, 2015.

SILVA, Mary Cristina Barros e. Repensando os Porões da Loucura: Um Estudo Sobre o Hospital Colônia de Barbacena. Belo Horizonte: Argvmentvm, 2008.

VELLOSO, Herculano. Ligeiras Memórias da Vila de São José: nos tempos coloniais. Tiradentes: IHGT, 2013.

Artigo:

Recebido em 10 de Maio de 2016 Aceito em 07 de Outubro de 2016.

R. Inter. Interdisc. INTERthesis, Florianópolis, v.14, n.1, p.79-97 Jan.-Abr. 2017 